\title{
Effect of Yoga on Heart Rate, Blood Pressure, Body Mass Index.
}

\author{
Dr.P.Satyanarayana ${ }^{1}$, Dr.G.Vijaya Benerji ${ }^{2}$, Rekha Kumari Dulala ${ }^{2}$, \\ Farid Babu Meka ${ }^{2}$,N.Ratna Kummari ${ }^{3}$ \\ 1.Professor and Head,Department of Physiology, Konaseema Institute of Medical Sciences, Amalapuram, \\ East Godavari Dist., A.P. , India \\ 2.Department of Biochemistry, Konaseema Institute of Medical Sciences, Amalapuram,East Godavari Dist., \\ A.P. , India \\ 3.Tutor, Department of Physiology, G.S.L Medical College,Rajahmundry, EG district, Andhra Pradesh, India
}

\begin{abstract}
Background: Yoga is an ancient Indian system of exercise and therapy, is an art of righteous living or an integrated system for the benefit of the body, mind and inner spirit. Regular practice of Yoga can help to decrease stress and anxiety. Forward bends such as the Paschimottana Asana help to increase blood flow to the brain, reduce stress, have a calming effect on the nervous system, and greatly help in reducing hypertension. Aim: The aim of yoga is the attainment of the physical, mental and spiritual health and to control the blood pressure. The present study was conducted to determine the effect of yoga training on 50 male (with or without CAD) subjects.

Methods: We examined the effects of yoga on hemodynamic and laboratory parameters in a 6-months pilot study. A course in yoga was given to all the subjects for 1.5 Hours six days in week for twenty four weeks. Systolic and diastolic blood pressures, heart rate, body mass index (BMI) were all studied, before and after 6months of yoga practice.

Results: This prospective cohort study included 50 subjects (mean age $52 \pm 2$ years) both with $C A D(30 \%)$ and without established coronary artery disease (CAD) (70\%). Yoga training causes decrease in systolic blood pressure (SBP) (average 20\%), mean arterial pressure (MAP) (11\%), heart rate (HR) (average 12.5\%) and BMI (8\%). SBP, HR and BMI value shows statistically highly significant ( $p<0.05)$. These results suggest that there is a significant reduction in blood pressure, heart rate, and BMI in the total cohort with yoga.
\end{abstract}

Conclusion: Yoga appears to control blood pressure of CAD patients.

Key words: Yoga, heart rate, blood pressure, coronary artery disease and body mass index.

\section{Introduction}

YOGA is defined as The physical practice of yoga postures that is a form of exercise. The word yoga means "union" in Sanskrit, the language of ancient India where yoga originated. We can think of the union occurring between the mind, body and spirit. What is commonly referred to as "yoga" can be more accurately described by the Sanskrit word asana, which refers to the practice of physical postures or poses.Asana is only one of the eight "limbs" of yoga, the majority of which are more concerned with mental and spiritual well-being than physical activity. In the West, however, the words asana and yoga are often used interchangeably.

There are so many famous known asanas like, Viparita dandasana, Adho mukha vikasana,Adho mukhasvanasana, Chaturanga dandasana,Padmasana,Matyasana, Kurmasana, Sukhasana, Vajrasana, Natarajasana,Hanumanasana,,Garbhasana, Sirshasana,Dhanurasana, Siddhasana, Anjaneyasana, Bhujangasana, Anantasana,Among these asanas, Viparita dandasana, Adho mukha vikasana,Adho mukha svanasana, Chaturanga dandasana are useful for our studies. We have selected, adho mukha svanasana in our study on fifty subjects.

Yoga is an ancient system of self-development which offers a holistic approach to man through its ideology \& techniques. Yoga is a science and its practice harmonizes the body and mind [1]. Yoga is immensely useful for promoting total health. Yoga is an alternative form of physical activity which may assist in achieving recommended levels of physical activity for some individuals. Yoga is increasing in popularity [2,3\&4]. with a recent report suggesting that 15 million Americans have practiced yoga at least once in their lifetime [5]. It also works effectively as a therapy in three ways - preventive, curative, rehabilitative. The yoga therapy has proved its excellence in psychological disorders and hypertension [6,7\&8]. Hypertension represents one of the most prevalent chronic conditions in Indian population [9]. The main cause of hypertension is stress and tension. Yoga can prove to be very effective in dealing with stress and blood pressure. It can fight the causes, as well as the effects of high blood pressure and stabilize blood pressure thus reducing high blood pressure. Asanas calm 
the mind and regularize and balance the nervous system, the center that controls stress. The sympathetic and parasympathetic nervous system, which is involved in stress reaction also get stabilized in the practice of asanas resulting in regulation of the blood pressure. The asanas, which regulate blood pressure, belong to the forward bends, supine, sitting, and inversions group. However forward bends are the fundamental asanas to be practiced by persons suffering from high blood pressure, whereas adho mukha svanasana is the most beneficial asana for blood pressure. The horizontal position of the spine in these asanas allows the heart to slow down, as there is no stress to pump the blood against gravity to the brain. The heart rate and the cardiac output simultaneously slow down and blood pressure is controlled.

\section{Methods}

Study population: We have conducted this study with 50 subjects (mean age $52 \pm 2$ years) both with $\mathrm{CAD}(30 \%)$ and without established coronary artery disease (CAD) (70\%). We examined the effects of yoga on hemodynamic and laboratory parameters in a 6-months pilot study.

We have selected the subjects from Konaseema institute of medical sciences, Amalapuram ,EG district, Andhra Pradesh, India. Inclusion criteria of the subjects are healthy subjects with out coronary artery disease (CAD), and subjects with coronary artery disease ( CAD), Elimination criteria of the subjects are, other cardiovascular diseases, vascular diseases pulmonary diseases. The study protocol was ethically approved by the institutional ethical committee. An informed consent of the volunteers was taken on an approved proforma.

Yoga practice: A course of yoga practice was given to all the subjects for 1.5 Hours six days in week for twenty four weeks.

Assessment of Body mass Index: BMI was calculated from weight (kilograms) divided by height (meters) squared by Quetelet index [10,11\&12].

Measurement of Pulse rate: The heart rate can be assessed by recording the electrocardiogram. (R-R. interval. ).ECG recorded by CARDIART 6108 (BPL) ECG machine. The instantaneous heart rate is measured from the interval between successive R-R interval of ECG.

Measurement of Blood pressure: Blood pressure was measured by the auscultatory method in the right arm in supine, sitting and standing positions, using a mercury sphygmomanometer with a cuff of $12 \mathrm{~cm}$ width. All the subjects were made to rest for at least 10 mins before taking the readings. The manometer cuff was snugly tied around the arm with tubing on the medial and the lower side. Systolic blood pressure was recorded to the nearest $2 \mathrm{~mm}$ of $\mathrm{Hg}$ at appearance of first Korotkoff sound, and diastolic blood pressure was recorded to the nearest 2 $\mathrm{mm}$ of $\mathrm{Hg}$ at the disappearance of Korotkoff sound. Systolic and diastolic blood pressure was recorded first in supine position, and then the standing position, with cuff tied to the arm. Readings were taken in all three positions and were analyzed [13].

\section{Results}

Fifty subjects (mean age $52 \pm 2$ years) were selected in this study and they are categorized into two groups based on their heart disease. In the first group (30\% or 15 subjects) were established coronary artery disease (CAD) where as the second group ( $70 \%$ or 35 subjects) without established coronary artery disease (CAD).

The baseline criteria in CAD subjects before starting yoga practice ,heart rate, systolic blood pressure, diastolic blood pressure and BMI parameters were measured by maintain standard procedure. After completion of twenty four week yoga course again all the parameters were analyzed and results were depicted in (Table 1). Heart rate decreases from $90.2 \pm 9,8 \mathrm{bpm}$ to $82.8 \pm 6 \mathrm{bpm}$, systolic blood pressure decreases from $152-4 \pm 8.3 \mathrm{~mm}$ $\mathrm{Hg}$ to $130.7 \pm 10.1 \mathrm{mmHg}$, diastolic blood pressure decreases from $90.8 \pm 4.2 \mathrm{~mm} \mathrm{Hg}$ to $88.3 \pm 3.9 \mathrm{mmHg}$, mean arterial pressure from $110.2 \pm 8.1 \mathrm{~mm} \mathrm{Hg}$ to $100.6 \pm 6.4 \mathrm{mmHg}$, body mass index decreases from $28.6 \pm 3$ to 26.8 \pm 4 . Yoga training produces decrease in SBP, DBP,MAP, HR and BMI. All four value shows statistically highly significant $(\mathrm{p}<0.05)$. These results suggest that there is a significant reduction in blood pressure, heart rate, and BMI in the total cohort with yoga (Fig 1).

Table 1: BASELINE REOCRDING OF PARAMERERS BEFORE STARTING YOGA PRACTICE AND AFTER COMPLETION OF 24 WEEKS YOGA PROGRAMME IN SUBJECTS WITH CAD (coronary artery disease )

\begin{tabular}{|l|l|l|l|l|l|l|}
\hline & AGE & BMI & HR & SBP & DBP & MAP \\
\hline $\begin{array}{l}\text { With CAD- } \\
\text { Before yoga. }\end{array}$ & $51.7 \pm 2-5$ & $28.6 \pm 3$ & $90.2 \pm 9,8$ & $152-4 \pm 8.3$ & $90.8 \pm 4.2$ & $110.2 \pm 8.1$ \\
\hline $\begin{array}{l}\text { With CAD- } \\
\text { After yoga. }\end{array}$ & $51.7 \pm 2-5$ & $26.8 \pm 4$ & $82.8 \pm 6$ & $130.7 \pm 10.1$ & $88.3 \pm 3.9$ & $100.6 \pm 6.4$ \\
\hline
\end{tabular}


Figure 1: COMPARISON OF BLOOD PRESSURE BEFORE AND AFTER YOGA.

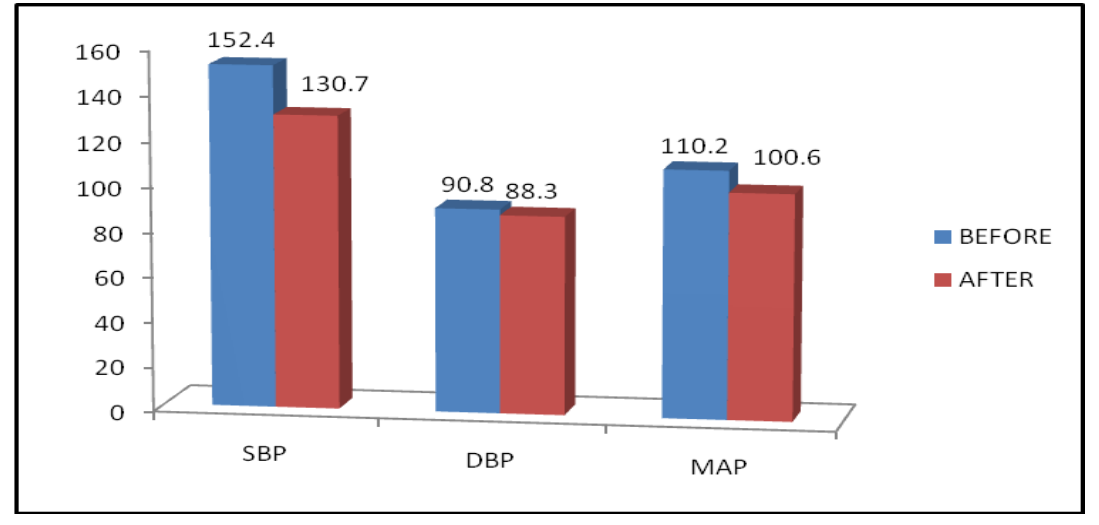

The baseline criteria in subjects without CAD, before starting yoga practice , heart rate ,systolic blood pressure, diastolic blood pressure and BMI parameters were measured by maintain standard procedure. After completion of twenty four week yoga course again all the parameters were analyzed and results were depicted in (Table 2). Heart rate decreases from $86.6 \pm 6 \mathrm{bpm}$ to $78.6 \pm 4.2 \mathrm{bpm}$, systolic blood pressure decreases from $140.6 \pm 10.1 \mathrm{~mm} \mathrm{Hg}$ to $124.2 \pm 9.3 \mathrm{mmHg}$, diastolic blood pressure decreases from $84.2 \pm 4.5 \mathrm{~mm} \mathrm{Hg}$ to $82.7 \pm 3.4$ $\mathrm{mmHg}$, mean arterial pressure from $106.4 \pm 6.4 \mathrm{~mm} \mathrm{Hg}$ to $98.4 \pm 3-2 \mathrm{mmHg}$, body mass index decreases from $25.2 \pm 2.6$ to $24.2 \pm 3$. Yoga training produces decrease in SBP, DBP,MAP, HR and BMI. All four value shows statistically highly significant $(\mathrm{p}<0.05)$. These results suggest that there is a significant reduction in blood pressure, heart rate, and BMI in the total cohort with yoga (Fig 1).

Table 2: BASELINE REOCRDING OF PARAMERERS BEFORE STARTING YOGA PRACTICE AFTER COMPLETION OF 24 WEEKS YOGA PROGRAMME IN SUBJECTS WITH OUT CAD (coronary artery disease )

\begin{tabular}{|l|l|l|l|l|l|l|}
\hline & AGE & BMI & HR & SBP & DBP & MAP \\
\hline $\begin{array}{l}\text { With out CAD- } \\
\text { Before yoga. }\end{array}$ & $50.7 \pm 1.8$ & $25.2 \pm 2.6$ & $86.6 \pm 6$ & $140.6 \pm 10.1$ & $84.2 \pm 4.5$ & $106.4 \pm 6.4$ \\
\hline $\begin{array}{l}\text { With out CAD- } \\
\text { After yoga. }\end{array}$ & $50.7 \pm 1.8$ & $24.2 \pm 3$ & $78.6 \pm 4.2$ & $124.2 \pm 9.3$ & $82.7 \pm 3.4$ & $98.4 \pm 3-2$ \\
\hline
\end{tabular}

From the above result we can find there is positive co-relation between BMI and hypertension. Men having CAD with higher BMI reported higher systolic and diastolic BP at baseline. As expected, men having $\mathrm{CAD}$ with higher BMI were more likely to have diabetes and high cholesterol.

\section{Discussion}

In our studies both in $\mathrm{CAD}$ subjects and without $\mathrm{CAD}$ subjects all the parameters like heart rate, systolic blood pressure, diastolic blood pressure and body mass index decreases after yoga than before yoga.

Hypertension is a major public health problem in India and in other developing countries [14\&15].This study demonstrates that continuous yoga training is associated with a significant increase of cardiac vagal modulation among healthy yoga practitioners. Since this method is easy to apply with no side effects, and leads to a deep physical and mental relaxation, it could be a suitable intervention during cardiac rehabilitation to shift the autonomic balance towards an increase of vagal activity and possibly decrease cardiac mortality.

Our analysis showed significant correlation between hypertension with higher age, body mass index which was an indicator of obesity and history of target organ dysfunction, multivariate analysis using the logistic regression only documented older age, non vegetarian diet and increasing BMI had significant influence on prevalence of hypertension. The relation of hypertension with advancing of age and BMI has already been documented in the past among Indian subjects [16].

In this study, progressively higher BMI was positively and significantly associated with an increased risk of incidence of hypertension. Our findings are consistent with a cohort of coronary artery disease for twenty four weeks. In this study, baseline BMI was associated with increased risk of hypertension defined as new antihypertensive medication use.

\section{Conclusion}

Hypertension has been perceived as a common and serious problem in the community. Yoga practice with a portion of sun salutation postures exceeding the minimum about of 10 minutes may contribute some portion of sufficiently intense physical activity to improve cardio-respiratory fitness in CAD individuals. 
What is very difficult, laborious, arduous, and strenuous is the achievement of absolute mental silence in all and each one of the forty-nine subconscious departments of the mind.True happiness cannot exist within each one of us while we are slaves to the mind.

This study demonstrates that relaxation by yoga training is associated with a significant increase of cardiac vagal modulation among healthy yoga practitioners. Since this method is easy to apply with no side effects, and leads to a deep physical and mental relaxation, it could be a suitable intervention during cardiac rehabilitation to shift the autonomic balance towards an increase of vagal activity and possibly decrease cardiac mortality.

Further studies are required to investigate whether the demonstrated positive effect of therapeutic yoga on the cardiac vagal modulation can be transferred to cardiac patients and introduced into cardiac rehabilitation programs.

\section{Acknowledgement}

Financial help was not taken from any funding agencies

\section{Referrences}

[1]. Nayak NN, Shankar K. Yoga: a therapeutic approach. Phys Med Rehab Clin N Am 2004;15:783-98

[2]. Garfinkel M, Schumacher HR., Jr. Yoga. Rheum Dis Clin North Am. 2000;26: 125-32, x. doi: 10.1016/S0889-857X(05)70126-5.

[3]. Chandler K. The emerging field of yoga therapy. Hawaii Med J. 2001;60:286-287

[4]. Raub JA. Psychophysiologic effects of Hatha Yoga on musculoskeletal and cardiopulmonary function: a literature review. J Altern Complement Med. 2002;8:797-812. doi: 10.1089/10755530260511810.

[5]. Saper RB, Eisenberg DM, Davis RB, Culpepper L, Phillips RS. Prevalence and patterns of adult yoga use in the United States: results of a national survey. Altern Ther Health Med. 2004;10:44-49.

[6]. Kreitzer MJ, Gross CR, Ye X, Russas V, Treesak C. Longitudinal impact of mindfulness meditation on illness burden in solidorgan transplant recipients. Prog Transplant 2005;15:166-72.

[7]. Madanmohan, Udupa K, Bhavanani AB, Shatapathy CC, Sahai A. Modulation

[8]. of cardiovascular response to exercise by yoga training. Indian J Physiol Pharmacol 2004; 48:461-5.

[9]. McCaffrey R, Ruknui P, Hatthakit U, Kasetsomboon P. The effects of yoga

[10]. on hypertensive persons in Thailand. Holistic Nurs Prac 2005;19:173-80. Vasan RS, Beiser A, Seshadri S, Larson MG, Kannel WB, D’Agostino RB, Levy

[11]. D. Residual lifetime risk for developing hypertension in middle-aged women and men:The Framingham Heart Study. JAMA 2002;287:1003-1010.

[12]. Garror J.S., Webster J.D. Quelet's index (W/H²) As a measure of fatness. Int J of Obesity 1985 9(2)147 53.

[13]. The clinical guidelines of the Identification, evaluation, and Treatment of overweight and obesity in adults: The evidence Report. National Institute of Health Publication 98-4083, Obes Res 1998; (suppl2):51S-209S.

[14]. World Health Organization. Obesity: Preventing and managing the Global Epidemic. Report of a WHO Consultation of Obesity. Geneva, 3-5 June 1997.

[15]. He J., Klag M.J., Whelton P.K., Chen J.U., Qian M.C. and He G.Q. Body mass and blood pressure in a lean population in Southwest China. Am J Epidemiol 1994; 139:380-9.

[16]. Nissien A, Bothig S, Grenroth H, Lopez AD. Hypertension in developing countries. World Health Stat Q. 1988;41:141-154.

[17]. [15]. Reddy KS. Hypertension control in developing countries: generic issues. J Hum Hypertension. 1996;10:S33-38.

[18]. Gupta R. Meta analysis of prevalence of hypertension in India. Indian Heart Journal. 1997;49:43-48. 